\title{
Alternatives to ward admission from the Emergency Department
}

Penelope A Bryant ${ }^{1,3,4}$, Sandy M Hopper ${ }^{2,3}$

1 Departments of General Medicine and RCH@Home

2 Emergency Department

3 Murdoch Children's Research Institute

4 Department of Paediatrics, University of Melbourne

The Royal Children's Hospital Melbourne, Parkville, VIC 3052, Australia $\longrightarrow$

Type of paper: Review

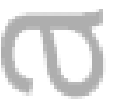

Key words: Short Stay Unit; Observation Ward; Home Care Services, Hospital-

Based, Hospital-in-the-Home

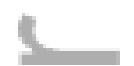

Corresponding author:

Penelope Bryant

Department of General Medicine

The Royal Children's Hospital Melbourne

Parkville

VIC 3052

Tel: 0393455522

This is the author manuscript accepted for publication and has undergone full peer review but has not been through the copyediting, typesetting, pagination and proofreading process, which may lead to differences between this version and the Version of Record. Please cite this article as doi: $10.1111 /$ jpc. 13100

This article is protected by copyright. All rights reserved. 
Email: penelope.bryant@rch.org.au

\section{Abstract}

There is ever-increasing pressure on hospital resources in general, and emergency departments (ED) in particular. At the same time, there is increasing recognition that traditional inpatient ward-based care is not necessary for the majority of children presenting to the ED with acute illness, and that there are patient, family and hospital benefits to pursuing other options. Here we describe alternative pathways for children presenting to the ED, including short stay and observational medicine, hospital-in-the-home and non-admission enhanced care, in other words additional management practices or pathways for children who are discharged from the ED. We discuss the principles, models and practical considerations involved in each of these.

\section{Key points}

1. The majority of children admitted from the emergency department (ED) with acute illness do not need admission to a traditional hospital ward. Tre

2. Short stay and ED observation units provide successful models for quick turnaround hospital care for children with well-circumscribed illnesses with clear management and discharge plans. 
3. Hospital-in-the-home programs provide hospital interventions in the home, allowing a child to remain out of hospital safely, with demonstrated psychosocial and cost benefits.

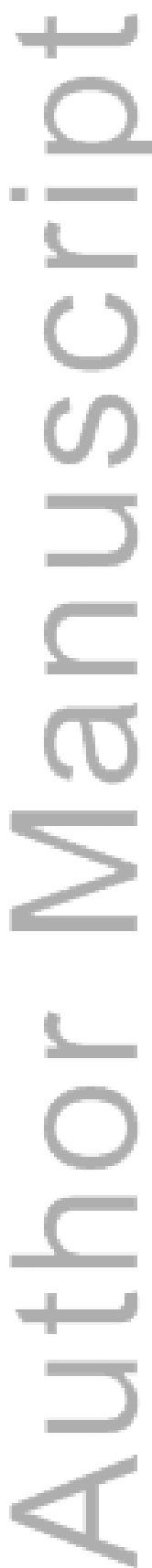

This article is protected by copyright. All rights reserved. 


\section{Introduction}

Admission from the emergency department (ED) occurs when a patient requires treatment that cannot be provided at home, observation for deterioration or manifestation of a serious illness, access to other staff or inpatient services, complex coordination of care, or to provide respite and reassurance.

Admission to hospital disrupts normal family function, subjects patients and parents/carers to sleep deprivation and psychological distress, and exposes the patient to the risk of hospital-acquired infection, medical error and environmental harm ${ }^{1}$. It is also costly, and as health care resources fail to keep pace with demand, EDs increasingly suffer from overcrowding. Therefore alternative pathways that avoid traditional ward admissions and shorten treatment times for those who need hospital care are more attractive than ever.

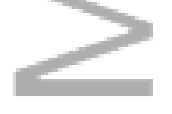

Medical conditions that are readily identifiable and/or have predictable rapid resolution are amenable to streamlined care. Most children and young people have no major co-morbidities, suffer from single system disease and improve quickly. A large proportion of their diseases and injuries have well-defined treatments and most patients respond predictably. For example, studies have found that the average length of stay for acute asthma is 39 hours $^{2}$ and $15 \%$ of hospital stays for children are less than 24 hours duration ${ }^{3}$. In addition, some traditional inpatient treatments can be given at home, especially in light of improvements in 
communication technology and pharmacology. The majority of children want to be at home and have an available parent/carer.

Therefore paediatrics is particularly suited to short stay units, quick turnaround observation units, ED procedural care, hospital-in-the-home, and other nonadmission enhanced care. This article will outline the principles, models and practical considerations pertaining to these alternatives to traditional ward admission from the ED.

\section{Short stay and observation medicine}

\section{Definition}

Whilst definitions overlap, in general terms, observation medicine describes hospital care episodes of 4-24 duration, and short stay describes 12-48 hours (occasionally up to 72 hours). The type of care may be investigation, treatment or monitoring of children with straightforward presentations that are amenable to pathways and guidelines ${ }^{4,5}$. Patients whose presentations or circumstances are complex are not appropriate for short stay care. The care plan should be standardised or at least well circumscribed, and the child should be able to be discharged as soon as the clinical condition improves. In this way, both the patient and hospital will maximally benefit from the model of streamlined care and lowintensity staffing. Administrative oversight, policy, procedures, governance and quality monitoring should at least equal those of an ED or inpatient unit. 


\section{Background}

Approximately one third of paediatric admissions from the ED are suitable for an observation unit ${ }^{6}$ and another third to half for a short stay unit (SSU) ${ }^{7}$. These illnesses can encompass up to $80 \%$ of emergency admissions in a non-tertiary setting, but probably a smaller percentage in a tertiary setting due to the larger numbers of complex cases ${ }^{8}$. Eligibility and destination relate to the disease and skill mix in any particular unit. Different unit models exist, for example inpatient team-led or ED-led, weekdays or seven-day operation and based on inclusion criteria or exclusion criteria ie whether it is the default admission pathway. Beyond the principles outlined above, the particular staffing model, target patient group, location and business rules of such units develop uniquely within each institution in the context of demand, patient mix, staff skills and available space and financial resources. For instance, a large ED in a tertiary paediatric centre may aim to relocate patients who need 3-8 hours of care from ED trolleys, thereby freeing both ED cubicles and inpatient beds ${ }^{9}$, whereas a mixed community ED with no inpatient paediatric beds might reduce transfers to other centres and improving access to paediatric staff'. Demand for the use of SSUs may vary over time, either because of changing patient conditions (eg after introduction of vaccines ${ }^{10}$ ) or changing provision of other services (eg implementation of hospitalin-the-home programs - see below). Monitoring variations allows SSUs to respond to changes in demand. 
Potential benefits of short stay care ${ }^{11,12}$ include: reduced inpatient time ${ }^{13,14}$, improved patient and parent comfort and satisfaction ${ }^{7,9,15-18}$, cost effectiveness ${ }^{9,14}$, 18-20, improved ED flow, improved patient access and reduction in inpatient hospital admissions ${ }^{9}, 20-22$. A successful short stay admission constitutes disease improvement, discharge within the pre-defined timeframe, and no unplanned return with the same disease. However, short stay admissions do not automatically equate to improved hospital efficiency ${ }^{23}$ and in one study there was a high rate of seeking medical advice after discharge ${ }^{15}$.

It is therefore important to ensure quality of short stay care is assessed. An unplanned representation or transfer-to-ward rate of up to $10 \%$ may be acceptable, although depending on the objective for the unit higher proportions may be tolerated ${ }^{24}$. Audits help to identify patient factors (co-morbidities, need for specialist consultation) or systems factors (lack of weekend admissions, inaccessibility of diagnostic investigations) that predict stays beyond the guideline time for the unit $25,26$.

\section{Practical considerations}

Paediatric observation units and SSUs typically cater for patients with simple medical or surgical conditions that have a clear management pathway: asthma, croup, pneumonia, bronchiolitis, gastroenteritis, cellulitis, lymphadenitis, urinary 
tract infection, febrile seizures, abdominal pain, head injury, overdoses or poisonings. Each unit may define targeted admission diagnoses according to its model of care (staff level and skill, rostering practices, length of stay criteria). Children whose presentations are poorly differentiated, who have complex comorbidities or social needs, who require extensive investigations or who are at risk of deterioration or deviation from a predicted course of recovery should are unlikely to have short admissions and should be excluded. At admission, patients should have a clear diagnosis and treatment plan or, if the diagnosis is unclear, a short and circumscribed differential diagnosis with a clear set of desired endpoints. Admissions should be approved by sufficiently experienced staff. Discharge criteria should be pre-defined and standardised where possible so patients can leave as soon as criteria are met. The practice of nurse-initiated criteria-led discharge is suited to short stay care, for which unambiguous discharge criteria and instructions are important ${ }^{15}$.

Finally, there are some patients who traditionally would have been admitted to hospital, who, with the right ED resources and processes can be cared for entirely in ED. Patients with isolated limb injuries who need procedural sedation for suturing or fracture reduction are a prime example, as is incision and drainage of abscess. Appropriate medical interventions for this type of quick turnaround care include rapid nasogastric or oral rehydration, rapid bronchodilator therapy, or one dose of intravenous antibiotics in a well febrile child with a petechial rash pending 
blood cultures. Children receiving this type of procedural care are particularly amenable to rapid review (see Non-admission enhanced care below). This differs from ED observation or short stay care in that it usually involves a single procedure rather than a management pathway, and any improvement is expected to occur rapidly without the need for extended monitoring, and certainly within the target time frames of the ED.

\section{Hospital-in-the-home}

Definition

Hospital-in-the-home (HITH) programs offer clinical interventions in the home, usually once or twice a day, that would otherwise require the child to be an inpatient. They act as a hospital bed replacement service, and patients are considered to be on a virtual ward. At their most fundamental, all HITH programs have nursing staff who attend the patient at home to deliver hospital interventions under medical governance. These may include intravenous antibiotics and chemotherapy, hydration/respiratory/cardiac assessments, education and management of diabetes, eczema and infantile spasms, and management of nasogastric tubes and central venous catheters. Some HITH programs have, in addition, dedicated senior and/or junior medical staff, physiotherapists and pharmacists.

\section{Background}

This article is protected by copyright. All rights reserved. 
Although HITH-type services for children have been described since the 1970s, this has generally been for post admission, convalescent care (such as prolonged intravenous antibiotics for cystic fibrosis or bone and joint infection) ${ }^{27}$. In contrast to adult HITH services, referrals directly from the ED for children is a novel concept.

-

There are benefits of a HITH admission versus an inpatient admission for both the patient and hospital. Patients have improved psychological outcomes on HITH compared to inpatient wards, and given the choice most children and parents prefer to be at home ${ }^{28,29}$. Patients also have reduction in the risks associated with hospital admission such as hospital-acquired infections, medical error and environmental injury. From a hospital perspective, it frees a bed for another emergency or elective patient, and it is more cost-effective with a HITH bed being about a quarter to a third of the cost of a hospital bed ${ }^{30}$. From an ED patient flow perspective, not having to wait for an inpatient bed can reduce time in $\mathrm{ED}^{31}$.

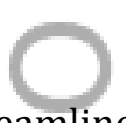

Streamlined referral from ED requires clear guidelines, easy communication, minimal paperwork and coordination on behalf of the referring ED clinician, and an assurance that the appropriate care and monitoring will occur. For this, the HITH service needs robust resourcing, including 24 hour nursing support and medical cover extending into weekends. Additionally, for ongoing care, rapid access to hospital services (such as medical imaging), clear communication and 
coordination with inpatient and emergency teams, and firm governance of patient care underpin the success of a HITH admission. Telemedicine can enhance HITH care and is feasible and acceptable to families. ${ }^{32}$ In a collaborative approach, the Royal Children's Hospital Melbourne implemented a direct from ED to HITH pathway and in its first year showed high clinician and patient/parent satisfaction, a median length of stay of 3 days and a low readmission rate of $3 \%$ (compared to $6 \%$ for all HITH patients). ${ }^{33}$

Potential disadvantages include the risk of being 'out of sight, out of mind'. Medical staff may be concerned that deteriorations may go unnoticed ${ }^{34}$. However, this is partly due to lack of understanding that HITH does not equate to discharge, with at least daily review of the child by a senior nurse and 24 hour-a-day telephone access to the HITH team for parents. These concerns are not upheld in the literature where studies have found no increase in adverse events or complications in HITH patients over inpatients ${ }^{35}$. Even accepting that this may be due to the fact that patients are selected for HITH who are unlikely to develop complications, these are precisely the patients who therefore do not need to be in hospital.

Practical considerations

It is important that ED and HITH collaboratively determine a pathway for direct transfer to HITH. The patient and parent conditions for this include a clear diagnosis, treatment that can be given once (or perhaps twice) a day, and minimal 
risk of time-critical severe complication (eg septic shock, hypoxia), a safe and supervised home environment with parents/carers accepting the care plan.

Acute clinical conditions in patients presenting to the ED suitable for care under HITH include cellulitis, urine infection/pyelonephritis, infected eczema, pneumonia and lymphadenitis ${ }^{36}$. Given the requirement for once daily parenteral antibiotics, ceftriaxone and gentamicin are commonly used. This represents a departure from more frequent inpatient regimens, such as flucloxacillin and penicillin, and the risks of broad-spectrum antibiotics needs to be balanced against the risks of hospital admission. Certainly, ceftriaxone seems to be effective in skin/soft tissues infections and pneumonia, with low complication rates $35,37,38$. HITH may also be used to support children with chronic or developmental conditions presenting to ED to avoid a hospital admission.

\section{Non-admission enhanced care}

Finally, there are a number of services which are considered outpatient or postdischarge care which can provide extra support to a patient once they have gone home as an alternative to admission. These include ambulatory services, home services and rapid review.

Some medical interventions that are only needed for a few days may be able to be administered on an outpatient basis with the patient re-attending the ED or an 
ambulatory unit on a daily basis. The most common example of this is outpatient parenteral antibiotic therapy (OPAT), and for hospitals that do not have a paediatric HITH service, this is a way of providing intravenous antibiotics for stable patients (for example for cellulitis or UTI) without admitting them to hospital.

(1)

Home services can be delivered by Post Acute Care programs, which may be based in hospitals or the community and assist patients to recuperate at home after attendance at the ED or ward admission. These can involve nursing or personal care and aim to prevent re-attendance and readmission. Other community services may also enhance discharge such as community physiotherapy or visits by the Royal District Nursing Service.

Rapid review usually refers to a pre-booked early review appointment (often within a week) for a child whose disease trajectory is uncertain. This can act as a safety net and provide reassurance for ED clinicians and also parents when the diagnosis is not clear or when the condition may not improve as anticipated. Thereby a number of 'just in case' admissions may be avoided. This can be done in different ways, for example in a rapid review clinic with a paediatrician, in a clinic designated for this purpose in the ED, or with good communication, by the general practitioner.

This article is protected by copyright. All rights reserved. 


\section{Conclusion}

Alternative care pathways have benefits for the child, the family, and the health care system. Many unexploited opportunities exist for patients presenting to ED to receive alternative care to ward admission. By understanding the benefits of each option, and its limitations, clinicians can make decisions for their patients that enable a rational use of limited resources while providing improved comfort and well-being for their patients.

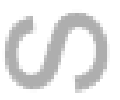

\section{Acknowledgments}

During this work, P Bryant was in receipt of a grant from the Victorian Department of Health entitled 'Improving the pathway between the Emergency Department and Hospital-in-the-Home.'

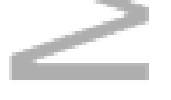

8

\section{References}

1. Hauck K, Zhao X. How dangerous is a day in hospital? A model of adverse events and length of stay for medical inpatients. Med Care.

2011;49(12):1068-1075.

2. South M. Reduction in length of hospital stay for acute childhood asthma associated with the introduction of casemix funding. Med J Aust. 1997;167(1):11-13.

This article is protected by copyright. All rights reserved. 
3. Numa A, Oberklaid F. Can short hospital admissions be avoided? A review of admissions of less than 24 hours' duration in a paediatric teaching hospital. Med J Aust. 1991;155(6):395-398.

4. Mace SE. Pediatric observation medicine. Emergency medicine clinics of North America. 2001;19(1):239-254.

5." - The Royal Children's Hospital Melbourne Clinical Practice Guidelines. http://www.rch.org.au/clinicalguide/.

6. Scribano PV, Wiley JF, 2nd, Platt K. Use of an observation unit by a pediatric emergency department for common pediatric illnesses. Pediatr Emerg Care. 2001;17(5):321-323.

7. Hopper SM, Archer P, Breene R, Bolt P, Sammartino L. Paediatric short stay unit in a community hospital: effective, efficient and popular. Emergency medicine Australasia : EMA. 2008;20(5):431-436.

8. Srivastava R, Homer CJ. Length of stay for common pediatric conditions: teaching versus nonteaching hospitals. Pediatrics. 2003;112(2):278-281.

9. Browne GJ. A short stay or 23-hour ward in a general and academic children's hospital: are they effective? Pediatr Emerg Care. 2000;16(4):223229.

10. Akikusa JD, Hopper SM, Kelly JJ, Kirkwood CD, Buttery JP. Changes in the epidemiology of gastroenteritis in a paediatric short stay unit following the introduction of rotavirus immunisation. Journal of paediatrics and child health. 2013;49(2):120-124. 
11. Daly S, Campbell DA, Cameron PA. Short-stay units and observation medicine: a systematic review. Med J Aust. 2003;178(11):559-563.

12. Ogilvie D. Hospital based alternatives to acute paediatric admission: a systematic review. Arch Dis Child. 2005;90(2):138-142.

13. Damiani G, Pinnarelli L, Sommella L, Vena V, Magrini P, Ricciardi W. The

= Short Stay Unit as a new option for hospitals: a review of the scientific literature. Medical science monitor : international medical journal of experimental and clinical research. 2011;17(6):SR15-19.

14. Marks MK, Lovejoy FH, Jr., Rutherford PA, Baskin MN. Impact of a short stay unit on asthma patients admitted to a tertiary pediatric hospital. Quality management in health care. 1997;6(1):14-22.

15. Arendts G, MacKenzie J, Lee JK. Discharge planning and patient satisfaction in an emergency short-stay unit. Emergency medicine Australasia : EMA. 2006;18(1):7-14.

16. Leduc K, Haley-Andrews S, Rannie M. An observation unit in a pediatric emergency department: one children's hospital's experience. Journal of emergency nursing: JEN : official publication of the Emergency Department Nurses Association. 2002;28(5):407-413.

17. Graham DA, Abbott GD, Dawson KP. A paediatric day ward: parental expectations, perceptions, and satisfaction. N Z Med J. 1991;104(920):405407. 
18. Rydman RJ, Roberts RR, Albrecht GL, Zalenski RJ, McDermott M. Patient satisfaction with an emergency department asthma observation unit. Academic emergency medicine : official journal of the Society for Academic Emergency Medicine. 1999;6(3):178-183.

19. Gaspoz JM, Lee TH, Weinstein MC, Cook EF, Goldman P, Komaroff AL, et al.

$=$ - Cost-effectiveness of a new short-stay unit to "rule out" acute myocardial infarction in low risk patients. Journal of the American College of Cardiology. 1994;24(5):1249-1259.

20. Browne GJ, Penna A. Short stay facilities: the future of efficient paediatric emergency services. Arch Dis Child. 1996;74(4):309-313.

21. Gouin S, Macarthur C, Parkin PC, Schuh S. Effect of a pediatric observation unit on the rate of hospitalization for asthma. Annals of emergency medicine. $1997 ; 29(2): 218-222$.

22. Lamireau T, Llanas B, Dommange S, Genet C, Fayon M. A short-stay observation unit improves care in the paediatric emergency care setting. European journal of emergency medicine : official journal of the European Society for Emergency Medicine. 2000;7(4):261-265.

23. Russell PT, Hakendorf P, Thompson CH. A general medical short-stay unit is not more efficient than a traditional model of care. Med J Aust. 2014;200(8):482-484.

This article is protected by copyright. All rights reserved. 
24. Crocetti MT, Barone MA, Amin DD, Walker AR. Pediatric observation status beds on an inpatient unit: an integrated care model. Pediatr Emerg Care. 2004;20(1):17-21.

25. Lucas BP, Kumapley R, Mba B, Nisar I, Lee K, Ofori-Ntow S, et al. A hospitalist-run short-stay unit: features that predict length-of-stay and

= eventual admission to traditional inpatient services. Journal of hospital medicine : an official publication of the Society of Hospital Medicine. 2009;4(5):276-284.

26. Yong TY, Li JY, Roberts S, Hakendorf P, Ben-Tovim DI, Thompson CH. The selection of acute medical admissions for a short-stay unit. Internal and emergency medicine. 2011;6(4):321-327.

27. Rucker RW, Harrison GM. Outpatient intravenous medications in the management of cystic fibrosis. Pediatrics. 1974;54(3):358-360.

28. Montalto M. Patients' and carers' satisfaction with hospital-in-the-home care. Int J Qual Health Care. 1996;8(3):243-251.

29. Sartain SA, Maxwell MJ, Todd PJ, Haycox AR, Bundred PE. Users' views on hospital and home care for acute illness in childhood. Health Soc Care Community. 2001;9(2):108-117.

30. Dougherty GE, Soderstrom L, Schiffrin A. An economic evaluation of home care for children with newly diagnosed diabetes: results from a randomized controlled trial. Med Care. 1998;36(4):586-598. 
31. Ibrahim LF, Hopper SM, Babl FE, Boyce SL, Bryant PA. The CHOICE Study: Cellulitis at Home Or Inpatient in Children from Emergency. Australasian College of Emergency Medicine Annual Scientific Meeting. Melbourne, Australia 2014.

32. Bryant PA, Ibrahim LF, Sacks B, Golshevsky D, Spagnolo M, Layley M, et al.

= Acute medical review by mobile telemedicine for children in hospital-inthe-home: an innovation. Arch Dis Child. 2014.

33. Sacks B, Hodgson KA, Ibrahim LF, Golshevsky D, Spagnolo M, Layley M, et al. Successful intervention to promote the use of hospital-in-the-home for patients referred directly from the Emergency Department. National HITH Annual Scientific Meeting. Sydney, Australia 2013.

34. Boyce SL, Ibrahim LF, Connell TG, Bryant PA. How many patients who could be cared for at home are being missed and why? National Hospital-in-theHome Annual Scientific Meeting. Melbourne, Australia 2014.

35. Ibrahim LF, Hopper SM, Babl FE, Bryant PA. A comparison of treatment at home to in hospital for moderate/sevre cellulitis in children. Australsian Society of Infectious Diseases Annual Conference. Adelaide, Australia 2014. 36. Bryant PA, Boyce SL, Sacks B, Nind B, Hopper SM, Babl FE, et al. Emergency department to paediatric Hospital-in-the-Home: maintaining momentum and quality of care. National HITH Annual Scientific Meeting. Melbourne, Australia2014. 
37. Chapman AL, Dixon S, Andrews D, Lillie PJ, Bazaz R, Patchett JD. Clinical efficacy and cost-effectiveness of outpatient parenteral antibiotic therapy (OPAT): a UK perspective. The Journal of antimicrobial chemotherapy. 2009;64(6):1316-1324.

38. Duncan CJ, Barr DA, Seaton RA. Outpatient parenteral antimicrobial therapy

= with ceftriaxone, a review. International journal of clinical pharmacy. 2012;34(3):410-417.

$\infty$

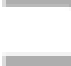

(19.

0

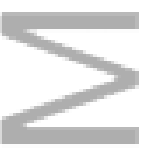

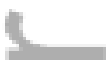

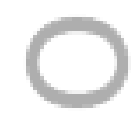

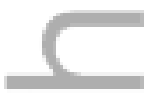

I

$+5$

2

This article is protected by copyright. All rights reserved. 


\section{University Library}

\section{- M M I N E R VA A gateway to Melbourne's research publications}

Minerva Access is the Institutional Repository of The University of Melbourne

Author/s:

Bryant, PA;Hopper, SM

Title:

Alternatives to ward admission from the emergency department

Date:

2016-02-01

Citation:

Bryant, P. A. \& Hopper, S. M. (2016). Alternatives to ward admission from the emergency department. JOURNAL OF PAEDIATRICS AND CHILD HEALTH, 52 (2), pp.237-240. https:// doi.org/10.1111/jpc.13100.

Persistent Link:

http://hdl.handle.net/11343/290876 